\title{
Fuentes escritas y tradición oral en interrogatorios procesales tardomedievales del centro-norte peninsular
}

\author{
ASIER ROMERO ANDONEGI \\ Universidad del País Vasco
}

\begin{abstract}
Resumen
Actualmente, nuestro conocimiento del castellano, que se manifiesta en el corpus notarial vizcaíno de los siglos XV y XVI, nos permite sugerir algunas cuestiones en torno a su emplazamiento en el marco de las variedades o dialectos del noroeste peninsular. Para llevar a cabo este análisis, se ha tomado como corpus una tipología procesal como es la probanza; analizándola, además, desde la tradición discursiva, punto de vista que tradicionalmente sólo la diplomática venía teniendo en cuenta.
\end{abstract}

\begin{abstract}
Our current knowledge of the Spanish that appears in the corpus of notarial documents from Vizcaya in the fifteenth and sixteenth centuries leads us to raise some problems concerning its place among the dialectal varieties of the central northern regions of the Peninsula. To carry out the present study I have used a corpus of probanza documents [oral testimony] from records of lawsuits, and analysed it from the point of view of its discourse tradition, which only experts in diplomatics (rather than in language) have so far taken into account.
\end{abstract}

La diplomática ${ }^{1}$ proporciona una base indiscutible para la elaboración de una tipología de textos, dado que las fórmulas lingüísticas y la solemnidad de cada documento se corresponden fielmente, gracias al conocimiento de los notarios, escribanos y amanuenses, con el tipo de negocio jurídico que se pone por escrito (Real Díaz: 1991), ${ }^{2}$ la calidad de su otorgante o procedencia, la relación distante

1 En inglés: 'diplomatics' o 'diplomatic': 'the science of diplomas, or of ancient writings, literary and public documents, that is, letters, decrees, charters, codicils, etc., etc., which has for its object to decipher old writings, to ascertain their authenticity, their date, signatures, etc.' (Oxford English Dictionary, from Webster 1828).

2 Es interesante en este punto observar la clasificación que elabora este autor dividiendo los documentos en dispositivos, probatorios, descriptivos y petitorios. En este mismo sentido se puede observar también la clasificación realizada por Andreas Wesch, que atiende a los continuos de condición comunicativa: 1 . Grado de publicidad del acto comunicativo 
o estrecha entre éste y el [los] destinatario[s] y el carácter público o privado del acto comunicativo que contiene. La diplomática se basa en todos estos elementos estructurales del documento para la elaboración de su tipología documental (Wesch 1994: 58). Existe en efecto una relación proporcional entre la publicidad del documento y su solemnidad, de modo que esta aumenta en aquellos textos en los que la distancia social entre los interlocutores es mayor. ${ }^{3}$ Por esto, en los escritos en que se manifiesten estos requisitos, como las cédulas reales u otro tipo de documentación solemne, resultará difícil hallar rasgos de oralidad, mientras que los documentos privados, aunque estén dirigidos al concejo, administración de justicia o al rey, se muestran mucho más flexibles respecto a tales tradiciones discursivas, ya sea por desconocimiento o por comodidad (Lorenzo Cadarso 1999: $152) ;^{4}$ por lo tanto es más probable encontrar errores o lapsus calami reveladores en los documentos privados y en las partes expositivas de aquellos cuyo carácter es público y solemne.

A estos factores se debe añadir el análisis sobre el estado de transmisión del documento que se está estudiando, ya que la información de él obtenida no puede valorarse del mismo modo si proviene de un original, una minuta, una copia simple o un traslado. Además, es preciso contar con la posición que el texto ocupa en la génesis del documento definitivo, resultante de la unión de actio (negocio jurídico de que se trata) y conscriptio (su puesta por escrito). Estas dos partes se componen de distintas fases de las que surgen documentos de categoría inferior a los que resultan de su unión, no dotados de solemnidad y, por esto mismo, de carácter simple. Así, José Joaquín Real Díaz denomina a este segundo tipo como documento lato sensu, y es precisamente en estos últimos, en los que conviene centrarse para observar si se produce una mayor presencia de errores gráficos o lapsus calami (Real Díaz 1991: 143).

Estas premisas son las que hacen que el tipo documental elegido para este análisis, la probanza, ${ }^{5}$ resulte interesante desde un punto de vista filológico, al tratarse de un tipo documental que recoge testimonios muy cercanos al habla $\mathrm{y}$, por tanto, permeable a esos lapsus calami tan reveladores. Cierto es que la

(privado o publico) y el número de interlocutores (un grupo delimitado o el pueblo íntegro); 2. El grado de familiaridad entre los interlocutores (entre mucha y muy poca familiaridad);

3. El grado de distancia social entre los interlocutores y una eventual relación jerárquica;

4. El grado de solemnidad del acto comunicativo (entre muy solemne y muy cotidiano).

3 En diplomática, según las formalidades utilizadas, los documentos pueden ser solemnes si cuentan con los elementos que delatan la soberanía (símbolos y fórmulas de autoridad) - o simples, si carecen de estos signos de solemnidad, aunque contengan los de autoría o función como la rúbrica notarial.

4 En este sentido ya señala este autor que: 'debe tenerse en cuenta que el grado de normalización de un documento es diferente según los tipos documentales, según sean públicos o privados y según épocas y culturas. Normalmente, los documentos públicos expedidos por chancillerías altamente burocratizadas tenderán a presentar un grado de formalización pleno, mientras que en el otro extremo, los documentos privados, tengan o no a la Administración como destinataria, reinterpretarán a menudo arbitrariamente las normas al uso por comodidad, capricho o desconocimiento'.

5 Emplearemos los términos 'probanza', 'cuestionario' o 'testificación indistintamente' para referirnos a este tipo documental. 
distribución de esos rasgos peculiares no es homogénea, pero como reiteradamente vienen defendiendo numerosos especialistas, la aparición, incluso accidental, de alguna particularidad en cualquier nivel lingüístico no carece en absoluto de valor informativo, porque puede tratarse precisamente de elementos del idiolecto del redactor que escaparían a la presión del modelo tipológico o 'estándar'. Nos enfrentamos, en palabras de Carmen Isasi:

Al fin y al cabo, a un hecho bien conocido por la crítica textual: la importancia de las circunstancias personales en las que se produce el texto; no es raro en efecto, que hallemos en un documento una concurrencia de rasgos menos habituales, bien porque el escribiente era menos instruido, bien porque se vio apremiado por la prisa o el cansancio. Se trata de un aspecto que no debemos ignorar al enfrentarnos a la metodología de un despojo global de testimonios y, lo que es más problemático, a su posible valoración cuantitativa. (Isasi Martínez 2002: 136)

Y desde vertiente diplomática, hay que señalar que en lo que respecta a la documentación notarial en concreto, la importancia otorgada al conocimiento de las tradiciones discursivas ha acrecentado la atención sobre una taxonomía, la de la tipología documental, que tradicionalmente sólo la diplomática venía teniendo en cuenta.

\section{II}

Hay que tener en cuenta que en los estudios de diplomática notarial, ya señalaba Ramón Santiago Lacuesta, autor de uno de los pocos estudios dedicados al análisis del notariado en textos norteños de las áreas alavesa, guipuzcoana o vizcaína, que 'la ausencia de todo otro tipo de textos escritos, incluso más allá de la Edad Media, en ciertas zonas de nuestra geografía, hace que nos hayamos de plantear con urgencia la recuperación de cuantos testimonios de nuestro pasado histórico-cultural han llegado hasta nosotros' (Santiago Lacuesta 1977: 238). ${ }^{6}$ La situación ha cambiado bastante desde esa fecha; las aportaciones de un buen número de investigadores han logrado que salgan a la luz numerosos textos antiguos, de manera que nuestro conocimiento de la diacronía del castellano en esta zona norteña va siendo cada vez mayor. ${ }^{7}$

Así mismo, el interés filológico de la documentación de esta franja cantábrica tardomedieval ya ha sido señalado en otros trabajos por diferentes autores ${ }^{8}$. Este

6 Esta importancia del acervo documental no literario para la reconstrucción de la historia lingüística peninsular ya ha sido señalada por diferentes autores, entre los que cabe destacar, por su reiterada reclamación, a Juan Antonio Frago.

7 Hay que subrayar en este punto la ingente labor realizada desde 1982 por la Sociedad de Estudios Vascos/Eusko Ikaskuntza para editar la colección Fuentes Documentales del País Vasco, herramienta imprescindible para la investigación de filólogos e historiadores en documentación medieval y tardomedieval del País Vasco y Navarra. En Cantabria, el proyecto DOHISCAN para la edición de documentación histórica de Cantabria ha sido fundamental para la recuperación de este patrimonio documental, poniendo al servicio de la investigación cerca de 40.000 documentos comprendidos entre los siglos IX al XVI.

8 Cabe destacar los diferentes artículos publicados por Carmen Isasi, y que se irán citando a lo largo del trabajo. 
interés se observa principalmente en lo que concierne a estas notas en el análisis de las peculiaridades de la lengua administrativa o notarial, ya que su conocimiento puede contribuir a una mejor redacción de la Historia del Arte de la Notaría en esta área peninsular.

El presente trabajo tiene como objetivo analizar la probanza, una de las principales tipologías documentales que integran un proceso judicial, en pleitos entre particulares de diferentes localidades de Vizcaya, Guipúzcoa, Álava, Burgos, Cantabria y Navarra y en cortes sincrónicos idénticos, principalmente del siglo XVI. Se ha seleccionado esta zona geográfica, principalmente, por dos razones: en primer lugar, por la ausencia de estudios sobre fondos notariales de áreas como la burgalesa y la cantábrica; y, en general, porque siguen faltando estudios comparativos hispánicos que se ocupen de tipologías homogéneas en cortes sincrónicos idénticos también. En segundo lugar, por el interés de caracterizar el castellano del País Vasco en el marco de su continuo dialectal castellano, que María Teresa Echenique definió como ‘continuo septentrional' (Echenique Elizondo 2006: 28).

De esta forma, nuestro análisis se enmarca en la caracterización del castellano de esta zona peninsular en el marco de su continuo dialectal. Lógicamente, asumimos como punto de partida el planteamiento de Penny cuando al explicar la distribución geográfica actual de rasgos lingüísticos en la Península, afirma que viene determinada por dos conjuntos de circunstancias: la existencia de un continuum dialectal septentrional, y la expansión territorial hacia el Sur de variedades norteñas que siguieron a la Reconquista de la España islámica. En palabras de Penny, ese continuum dialectal septentrional ocuparía de forma aproximada el tercio norte de la Península, y formaría parte del continuum dialectal romance que se extiende desde el Noroeste de España hacia Francia y desde allí hacia Bélgica, Suiza e Italia, por una parte, y hacia el continuum pirenaico, por otra (Penny 2004).

Esta argumentación concuerda con la teoría de María Teresa Echenique cuando alude a la confluencia de dos corrientes colonizadoras en la franja cantábrica, a saber, una que, procedente del Mediterráneo, penetraba en la Península remontando el curso del Ebro hacia su nacimiento, y otra que, desde la Aquitania, llegó al País Vasco rumbo al Noroeste peninsular (Echenique Elizondo 2006: 28). ${ }^{9}$ Además, entre el establecimiento del latín en la Península y la posterior invasión islámica en el siglo VIII, la totalidad de la Península debió formar un continuum dialectal. A este respecto, y como señala María Teresa Echenique:

Los dialectos del Norte peninsular constituirían los únicos segmentos de este continuum que han sobrevivido hasta el día de hoy, y entre ellos no cabe olvidar el románico inserto en la lengua vasca [...]. No cabe duda de que la zona vasca es parte del continuum norteño. Es, de hecho, el puente que une el Noroeste con el Noreste en unos casos, así como Hispania con la Aquitania en otros. La tarea aún pendiente es

9 A este respecto, son muy interesantes los novedosos descubrimientos que se están realizando en diferentes excavaciones de la costa vizcaína y guipuzcoana y que han llevado a valorar de nuevo la importante presencia romana en esta zona de la costa vasca. 
estudiar con mucha minuciosidad, a la luz de un planteamiento actualizado de la cuestión, si determinados hechos se deben a sustrato, a colonización de uno u otro carácter o bien a la combinación de ambos. (Echenique Elizondo 2006: 29)

Desde esta perspectiva, se pretende no solo definir el castellano de esta área sino también caracterizarlo con sus similitudes y divergencias, a la luz de otros entornos como el navarro o el leonés, es decir, en lo que se ha venido llamando como complejo dialectal castellano (García de Diego 1950). De esta forma, sin entrar en la amplia literatura existente sobre el reconocimiento de la variación interna del castellano norteño, ha sido norma común en las descripciones la asociación del castellano del norte de Burgos con un estándar burgalés gestado más al sur, o que se reconozcan en este castellano norteño características propias de otras variedades orientales $u$ occidentales..$^{10}$

A la vista del status quaestionis este intento de caracterización es bastante complejo para el periodo altomedieval por la ausencia documental, aunque los datos actuales, ya señalados, sobre la romanización en el área vasca y la línea de trabajos que desarrollan la propia María Teresa Echenique o Ángeles Líbano deberían ayudar a muchos replanteamientos.

Esta dificultad es menor para el periodo bajo y tardomedieval por el aumento considerable de documentos, y sobre todo por los trabajos llevados a cabo para esa etapa por el Seminario Alfonso Irigoien (SAI) de la Universidad de Deusto.

\section{III}

Desde el punto de vista de la estructura diplomática de las probanzas, hay que tener en cuenta que los documentos judiciales se encuentran aislados y se generaron siempre en el marco de un proceso sumarial. Ahora bien, la confusión que existía en la época (ss. XV y XVI) entre las tareas politico-administrativas y las judiciales originó que determinados tipos documentales fuesen utilizados indistintamente por todos los organismos burocráticos, fuese cual fuese su funcionalidad. Ahora bien, desde un punto de vista diplomático los documentos judiciales son aquellos que han sido generados normativamente durante la tramitación de un proceso, respondiendo por tanto a necesidades funcionales del procedimiento. ${ }^{11}$

Estos litigios llegaron a la Chancillería de Valladolid, por tanto son juicios en apelación instruidos por los tribunales reales. El Juez Mayor de Vizcaya, que instruye ahora el sumario, tiene como objetivo, en un primer momento, reconstruir los hechos y fijar las responsabilidades civiles o criminales de los sospechosos, para ello se van dictando una serie de órdenes: autos, que eran comunicadas a las partes mediante pregón, notificación, requerimiento o provisión real. Así, en

10 Han sido numerosos los especialistas que han tratado este tema, desde los planteamientos clásicos de Menéndez Pidal, García de Diego o Lapesa hasta las más cercanas de Frago o Morala.

11 La escasez de estudios sobre la práctica procesal castellana en los siglos XVI y XVII complica sobremanera cualquier reconstrucción de la misma, dado que lo único que realmente se conoce son los referentes normativos y algunos procedimientos muy concretos. 
los documentos 1 y 2 se comunica al alcalde municipal, mediante provisión real, la necesidad de realizar la probanza a petición de una de las partes. ${ }^{12}$ Por tanto, en primera instancia, estos cuestionarios los realiza el alcalde de la villa, como juez ordinario, junto con el escribano de la causa o del escribano 'acompañado', nombrado por una de las partes. ${ }^{13}$

[...] e dixieron que para la examinación de los dichos testigos e para todos los otros autos que en prosecución d'ella se abían de hazer, nombraban e nombraron por escrivano acompañado a Juan Ruis de Fradua, escrivano del número de la dicha villa, que presentes estaban sin el qual pedían e pedieron non mandasen hesaminar ninguno de los dichos testigos nin haser otros autos algunos de aquí adelante y el dicho señor allcalde lo recibió por tal e le tomó juramento en forma [...]. (Documento 2) ${ }^{14}$

Así pues, las probanzas están realizadas ante el alcalde ordinario de la villa, que actúa como juez ordinario, aunque posteriormente, por medio de un traslado hayan sido incorporadas al proceso que se lleva a cabo en el tribunal de apelación de la Chancillería. Este dato es importante, ya que son copias certificadas del sumario del proceso en instancias anteriores o de copias certificadas de documentos presentadas por las partes con finalidad probatoria (probanzas). ${ }^{15}$ Los traslados corresponden a veces a documentos originales presentados por los litigantes ante el tribunal:

E luego la dicha María Juana pedió las escrituras oreginales para los tener en su poder quedando los traslados en el proceso, el dicho comisario gelo mandó dar quedando los dichos traslados en el proceso concertados. (Documento 3)

En otros casos se trata de documentación generada en primera instancia ante el alcalde ordinario:

[...] este dicho proceso e autos en uno con el dicho Juez comisario e testigos e de pedimiento del dicho Martín abad de Açatarro e por mandado del señor Juez Mayor de las apelaciones de Viscaya saqué este dicho proceso e fiz escrivir en estas treinta e quatro fojas de papel [...]. (Documento 4)

Las probanzas están expedidas por los litigantes, por tanto su función procesal es probatoria. Su objetivo dentro de un proceso era aportar pruebas testificales de los testigos de los hechos, pero en estas probanzas no son interrogados los encausados. El interrogatorio lo realiza el alcalde (juez) y el escribano asignado a la instrucción levanta acta de todo lo acontecido.

12 'Probança fecha ant'el alcalde de la Noble villa de Vermeo, Cabeça de Viscaya, a pedimiento de San Juan de Arostegui por provisión real de su magestat en el pleito de Rogel Pavin Inglés'.

13 En su mayor parte, los escribanos que actúan pertenecen a la nómina de escribanos del número de la villa.

14 Véase el Apendice 1.

15 En los tribunales castellanos del Antiguo Régimen se le concedía mayor valor probatorio a una copia con validación notarial que a un original, ya que se consideraba que los públicos, validados notarialmente, eran de más valor que los particulares, a los que se les concedió siempre muy poco crédito, de ahí que las partes presentasen copias certificadas de documentos que poseían en original. 
Cada uno de los interrogatorios es un documento independiente con todos los requisitos formales presentes, ahora bien, a menudo se abrevian por cansancio del juez y escribano. El interrogatorio comienza con el auto del alcalde (juez) ordenando el procedimiento y cuantas diligencias fuesen necesarias para su ejecución: bando público convocando a los testigos, publicación de las preguntas, auto de aceptación de las preguntas, etc.

La relación de preguntas que se presentan van numeradas al margen.

Por las preguntas seguientes sean demandados los testigos que por parte del dicho goardián, frailes e convento del monasterio de San Francisco de la dicha villa de Vermeo son o fueren presentados, sobre lo contenido en una probisión real de sus altesas e sobre lo otro que conbiene la información ante su real consejo. E primeramente sean demandados sí han noticia [...]. (Documento 3)

Primeramente sean preguntados los dichos testigos si conocen [...]. (Documento 1)

El acta de interrogatorio comienza con la data crónica y tópica. A continuación, se presenta la relación de testigos de cada una de las partes, junto con la cláusula de juramento, que está realizado ante el alcalde y certificado por el escribano. ${ }^{16}$

A lo que los dichos testigos e cada uno de los presentados por el dicho San Juan de Arostegui dixieron e depusieron por sus dichos e depusiciones sobre juramento que primeramente hizieron seiendo preguntados cada uno sobre sí secreta e apartadamente por las preguntas generales e por las del dicho interrogatorio dixieron e depusieron lo seguiente.

[...] vecinos del lugar de los quales e de cada uno de ellos fue tomado juramento por Dios e por Santa María e por las palabras de los Santos Evangelios e por la señal de la Cruz tal como esta en forma de dercho testigos los dichos [...].

En cada una de las actas del interrogatorio se indica, también, al margen el número del testigo:

$\mathrm{t}^{\mathrm{o}}$ (testigo)

El cuerpo del documento comienza con la identificación del testigo, normalmente sus datos personales: nombre, vecindad, edad, parentesco con los encausados y otros datos que pueden ser significativos.

Respondiendo a las preguntas generales de la premática real de sus magestades, dixo que su hedad es treinta e dos años, poco mas o menos, e que no es pariente de ninguna de las partes en grado de consanguinidad, e non venía sobornado, corruto nin atemorizado por ninguna de las partes para desir el contrario de la verdad, e querría quien al que la justicia tobiese Dios le diese, e su dicho terna secreta fasta la publicación d'esta causa. (Documento 5)

El interrogatorio se desarrolla entre las siete (Documento 5) y las trece preguntas (Documentos 3 y 5). Cada pregunta comienza con la expresión 'íten si saben' (Documento 3), 'íten sean demandados si saben' (Documento 1). La respuesta se encabeza con la expresión 'A la primera pregunta dixo que sabe' (Documento 1), 'A la tercera pregunta dixo que sabe' (Documento 1).

16 En los documentos estudiados, la cláusula de juramento se realiza en conjunto para cada grupo de testigos que presenta cada una de las partes. 
El cuerpo del documento se cierra con una cláusula de ratificación del juramento tras la lectura pública por el escribano del acta. Le sigue otra de corroboración y la suscripción del alcalde (juez), del escribano y del propio testigo (en caso de que sepa escribir).

A la trezena e a todas las otras preguntas al caso pertenecientes dixo que se afirmaba en lo que dixo. E público e notorio. E firmó de su nonbre, Juan de Acorda, Juan de Hercilla, Pero Ferrándes y Juan Ruiz. (Documentos 3 y 4)

A la terçera pregunta dixo que dize lo que dicho tiene de suso en que se afirma e afirmo y es la verdad para el juramento que hizo e no lo firmo por que dixo que no sabia. (Documento 8)

Los documentos del corpus son traslados realizados por los escribanos encargados de las causas, que sacan la probanza o información a petición de una de las partes encausadas (iusso jurídica). De esta forma, no se registran las firmas correspondientes después de cada declaración, aunque el documento, a través de la validatio notarial, tiene toda la validez jurídica.

E yo el sobre dicho Pero Ferrándes de Miranda, escrivano de la cesárea e católicas magestades de los reyes, nuestros señores, e del número de la dicha villa, presente fui ant'el dicho señor alcalde, en uno con los dichos testigos a lo susodicho e de pedimiento del dicho Juan Gonsáles saqué e fis escrivir esta probança en estas honze fojas de papel con esta en que ba mi sino acostumbrado. E van cosidas una con otra, e en fin de cada una plana rubricadas de la mi rúbrica e ba cerrada e sellada. E por ende fis aquí este mío sig[signo]no, en testimonio de verdad. [firma y rúbrica] Pero Ferrándes. (Documento 4)

En esta breve exposición, se puede observar como los diferentes documentos analizados presentan un formulismo similar casi uniforme. Hay que tener en cuenta que nos encontramos ante documentos judiciales por lo que el respecto por parte de los escribanos a los formularios existentes es bastante significativo. ${ }^{17}$ Ahora bien, conviene recordar que aunque nuestros escribanos se movían con habilidad dentro de este código, una aproximación filológica resulta imprescindible en el análisis de los elementos elocutivos y de aquellos otros concernientes a la disposición del texto que son, en definitiva, sino un resultado retórico estereotipado del Ars Dictandi. ${ }^{18}$

Que las redacciones de los escribanos son en gran parte esteriotipadas constituye, en efecto, una circunstancia ampliamente constatada; ahora bien, los análisis más recientes van puliendo las aristas del tópico del ‘formulismo' y nos muestran ahora otras perspectivas en las que destacan la variedad de registros asociados a las diferentes tipologías o las modulaciones lingüísticas de un mismo escrito en consonancia con el desarrollo de su propia estructura (Isasi Martínez 2000: 282).

17 Muy diferente, sin duda, a las partes expositivas en las que se recogen las declaraciones de los testigos.

18 A través de la presencia reiterada de estructuras expositivas que caracterizan este tipo de textos podemos llegar a la conclusión que estos escribanos se desenvolvían con habilidad dentro de este código. De esta forma, es fácil identificar un mismo modelo documental fielmente seguido por un notario en diferentes ocasiones a lo largo de la transcripción de la probanza. 


\section{IV}

La creación de una escritura se inicia con la recepción de la declaración de voluntad de los otorgantes para redactar el negocio jurídico ante el escribano, asentándose sobre un simple apuntamiento (nota o minuta), que tras la Real Pragmática de 1503 pasa a convertirse en la inserción literal del texto originando el 'protocolo literal' (Bono Huerta 1985: 82). En un segundo momento se produce la formulación del negocio por escrito, a partir de la primitiva recepción de la nota medieval o por la transcripción de la escritura matriz en la Edad Moderna, esto es, la puesta en 'pública forma'. ${ }^{19}$ Al finalizar la elaboración del instrumento público nos encontramos con la presencia de dos documentos como reflejo de un mismo acto jurídico: la copia que permanecerá en manos de los otorgantes y el documento original que sirvió como consigna inicial del negocio que se queda en manos del notario (el protocolo inicial'.

De otro lado, la identificación del autor material de la matriz resulta muy difícil de fijar, dada la uniformidad que reviste la escritura en todo momento. ${ }^{20}$ No obstante, parece lógico que, disponiendo el notario de escribientes, hiciera uso de ellos. De esta forma el escribiente, previa orden del notario, traslada literalmente al nuevo texto el contenido de la matriz y el titular del oficio, por su parte, se limita a añadir de su propia mano la cláusula de autorización, que cierra el tenor de la escritura validándola. El notario o auctor documental, además, interviene personalmente en la ejecución material del documento desde el momento que autoriza, primeramente, con su firma y rúbrica la matriz y, en segundo lugar, con aquéllas y el signo, la escritura en 'pública forma'. Ahora bien, hay que tener en cuenta el distinto grado de competencia de cada uno de los escribanos, y el hecho de que no falten deslices puede deberse tanto al descuido como a la impericia. Las repercusiones de este hecho son importantes para el estudio de los documentos más inhábiles.

La firma del otorgante o del testigo en su caso, falta en numerosas ocasiones, al igual que la firma del escribano. ${ }^{21}$ Además, cuando el otorgante no sabe firmar,

19 El protocolo moderno, es decir, el posterior a 1503, recoge por extenso todos los negocios, de manera que entre el documento expedido y dicho asiento o escritura matriz van a existir exclusivamente dos diferencias: la primera se refiere a la completio notarial, que estará ausente en el registro y será imprescindible en la expedición definitiva del negocio. La segunda, a las suscripciones de los otorgantes en el libro registro, cuando éstos saben escribir, y, en caso contrario, su ruego para que lo hagan en su nombre.

20 Se presentan estos documentos a modo de ejemplo, ya que también se podría extender este hecho a otros textos aunque con una tipología diferente: Archivo Histórico de la Diputación Foral de Bizkaia (a partir de ahora 'AHDFB'), Sección corregimiento, 959 / 92, 1565; AHDFB, Sección corregimiento, 959 / 91, 1565; AHDFB, Sección corregimiento, 959 / 103, 1565. Se desconoce si su escrituración, total o parcialmente, corrió a cargo del notario o de uno o varios de sus amanuenses, pues lo único que se sabe escrito por el primero, con absoluta certeza, es su firma. Además, el cotejo de la firma con el tenor del documento, resulta prácticamente imposible.

21 La consulta en el Archivo Histórico Eclesiástico de Bizkaia de un Libro-Registro de codicilios del último cuarto del s. XVI, perteneciente a la Iglesia de Santa María, me permitió observar la sucesión de diferentes escrituras sin la presencia del signo notarial a la 
lo hace un testigo en su nombre, hecho que se manifiesta en el texto a través de fórmulas como: 'porque el dicho otorgante dixo que no sabía firmar por su ruego firmo el dicho'. El otorgamiento en las Partidas es oral, pero con la Pragmática sólo la firma personal o suplida por un testigo de él o de los otorgantes es validación del documento. Sería interesante comprobar si el documento que se expide lleva igual fecha que el que permanece en el registro, o si habitualmente aparecen las firmas otorgantes, escribano y testigos. ${ }^{22}$ En las probanzas no aparecen las firmas de los testigos, ya que se trata de traslados realizados por el escribano. Ahora bien, aunque no aparezcan las suscripciones de los otorgantes o las de los testigos, sí se comprueba la función testificativa del notario, quien no sólo añade su signo, sino que también lo menciona en el escatocolo.

En cuanto al análisis de la suscripción notarial y de su relación con la posible presencia de varias manos en la redacción del documento. Se identifican a menudo, en efecto, cambios de mano en los documentos que prueban la actuación de segundas o terceras personas junto al notario titular, aunque no resulta factible es determinar, a través de la suscripción notarial, el grado de participación de esas personas en la ejecución material de los correspondientes instrumentos. Con todo, se puede afirmar que el oficio notarial en el corpus, durante el periodo estudiado se estructura, cuanto menos, en torno a dos jerarquías, a saber: el escribano público del número/real, de un lado, y aprendices o amanuenses, de otro y que ambos tienen una distribución específica de funciones: el escribano manda escribir, signa y testifica, mientras que los escribientes escriben el mundum y testifican.

Ahora bien, en los documentos de este corpus de escribientes o amanuenses no dejan constancia de su labor como redactores del mundum a través de su firma, si bien su presencia queda reflejada en la subscripción a través de la iussio notarial, cuando se señala 'fiz escribir'. En el corpus, en seis ocasiones se registra la fórmula jurídica: 'fiz escribir', en siete ocasiones las variantes: 'fiz escribir y escrivi', 'escrivi e fiz escribir' y 'fize sacar y escribir', en cuatro ocasiones: 'escrivi' y en cuatro no hay constancia de la iussio notarial. Además, siempre se produce la correspondencia entre la iussio notarial y la actuación del escribano titular en la suscripción: propia mano = 'escrivi' y cambio de mano = 'fiz scribir'; con la excepción de los documentos que presentan la fórmula notarial 'fiz escrivir y escrivi', en los que siempre hay cambio de mano (documentos $2,5,8$ y 11).

finalización de cada registro. El signo notarial aparecía cuando se producía un cambio de mano, ahora bien en ningún momento se registran las firmas de testigos ni otorgantes. Estos datos coinciden con lo descrito por los estudiosos del notariado hispánico: Antonio Rodríguez Adrados (2005), Antonio José López Gutíerrez o Concepción Mendo Carmona.

22 A veces el escribano indica en la suscripción que los testigos u otorgantes ya habían firmado en el registro: 'e lo firmaron de sus nombres en el mi registro horeginal donde queda otro tanto en mi poder' (Documento 11). 


\section{V}

En este contexto a la hora de realizar un estudio lingüístico, hay que tener siempre presente que se trabaja con materiales escritos, redactados por escribanos y amanuenses más o menos cultos, por lo que no transmiten exactamente la realidad de la lengua hablada, más innovadora, es más, a menudo constituyen una simple acumulación de fórmulas notariales. No obstante, aunque actualmente entre los especialistas se va descartando la idea de redacción esteriotipada o lengua formularia para definir el lenguaje jurídico. Por otro lado, no debemos ignorar que las exigencias pragmáticas del escrito notarial requerían - y requieren - el esfuerzo de sus autores para lograr una eficaz adaptación de los moldes heredados de la rutina. Es una circunstancia ya advertida por diversos autores respecto a los documentos notariales del medievo y que sigue afectando a los documentos jurídicos de nuestros días. ${ }^{23}$

Por otra parte, ya hemos señalado que parece razonable aceptar que los autores de estos documentos conocían la rutina formal, aprendida sobre modelos ya existentes, transmitidos bien a través de la praxis, bien de la consulta de formularios.

Interesa poner de relieve en este sentido, que como señala Javier Terrado Pablo, la producción de un texto se concibe como: 'un proceso regulado por un código, el cual, dado un contexto social determinado, selecciona una variedad concreta de lenguaje' (Terrado Pablo: 1991). A las distintas variedades de lenguaje mediante las que puede actualizarse un código las denomina registros, siguiendo la acepción dada por M. A. K. Halliday (1978). Por tanto, aplicando la clasificación ofrecida por Javier Terrado, se nos presenta un único registro en nuestros pleitos: el registro testimonial, 'utilizado para anotar en estilo indirecto las palabras de los interlocutores’ (Terrado Pablo: 1991).

Esta testificación es el principal argumento lingüístico para considerar a la probanza como una de las más interesantes tipologías procesales, ya que en el caso que nos ocupa el escribano coloca en estilo indirecto las declaraciones de algunos testigos; ciertamente esas declaraciones han sido rehechas posteriormente a su recogida y el encargado de redactarlas pule su estilo, pero se pueden apreciar, unas pocas veces, unas pinceladas de la lengua hablada. En este sentido, Juan Antonio Frago ya señala que en los interrogatorios judiciales no es infrecuente que el escribano, haciendo gala de una gran exactitud, recoja con notable realismo las respuestas de acusados y testigos. Y aunque nos encontremos ante individuos mediana o altamente cultos, estos lapsus calami son tanto o más representativos que todo un cúmulo de faltas descubierto en un texto dado por la mano de quien apenas ha recibido docencia escolar (Frago Gracia 1987: 72). En esta misma línea, Javier Terrado describe a los registros coloquial y testimonial como:

23 Como señala Carmen Isasi: 'el problema especial del lenguaje jurídico reside en que, por un lado, debe servir como lenguaje especializado a la comunicación a los expertos del área, los juristas, y por otro se pretende que conserve la relación con la lengua común para que también la comprenda el ciudadano afectado' (Isasi Martínez 2000: 283). 
Los registros más cercanos al habla viva y espontánea. Por el hecho de reflejar las palabras pronunciadas por diversos personajes, permiten estudiar los componentes subjetivos y afectivos de la expresión y hacen patente el sistema de relaciones interpersonales establecido entre los hablantes. Son estos registros los que pueden brindar materiales para el estudio de la sintaxis propia de la lengua hablada. (Terrado Pablo 1991: 67)

Además, teniendo en cuenta los 'continuos de condición comunicativa' descritos por A. Wesch, las probanzas son tipos documentales simples y de publicidad inexistente, por lo que los índices de error gráfico o lapsus calami pueden aumentar considerable (Wesch 1994: 59).

El buen conocimiento de los cánones y de la rutina del Arte Notarial, que se observa a través de la estructura diplomática de las probanzas, no excluye las desviaciones debidas al distinto grado de competencia de cada uno de los escribanos. En los documentos del corpus aparecen deslices en los que probablemente se conjugan el descuido y la impericia, a través de los cuales se pueden entrever algunas huellas indirectas de la lengua hablada. ${ }^{25}$

Este hecho se observa en algunos de los documentos, caracterizados por presentar diferentes usos gráficos o fonéticos de hipotética rareza respecto a las soluciones aceptadas como más comunes en la scripta castellana de la época. Nos referimos a la secuencia gráfica <oa> y a la peculiar utilización de <ill $>$ en la secuencia <il> (goardar, goardian, agoa, pillotos, pillotaje, pilloto, ventillaban). Además, en los documentos del corpus estas secuencias aparecen en el cuerpo del texto redactado con un tipo de letra diferente al que se desarrolla en la suscripción. Por ello, nos preguntamos si la aparición de estos lapsus depende de la acción de un escribano o escribiente que, debido a un peor aprendizaje o, simplemente, a la rutinaria redacción de un traslado, hace que sus textos sean más permeables a las peculiaridades locales. La rapidez con que solían redactarse estos documentos, especialmente los interrogatorios judiciales, circunstancia que se hace visible en la tipología escrituraria utilizada (gótica cursiva procesal), explica el número de lapsus calami en los documentos, y que a nuestro juicio no debe entenderse siempre como una falta cultural del amanuense en cuestión, sino en el carácter rutinario que caracteriza a este tipo documental. ${ }^{26}$

24 A este respecto son interesantes las palabras de E. M. Rojas Mayer en relación con un corpus de documentos coloniales de América: 'En esta fase de la investigación pragmalingüística histórica no podemos afirmar aún con precisión que sea posible establecer pautas que nos permitan sistematizar el estudio de la lengua a partir de una supuesta realidad en tiempos remotos. Sin embargo, consideramos que es importante intentar el estudio del discurso de otras épocas, teniendo en cuenta las distintas piezas que lo componen como partes del entramado textual y auscultar qué es lo pertinente en cada caso, alternando la codificación y descodificación con las suposiciones necesarias al respecto' (Rojas Mayer 2002).

25 Con todas las reservas aplicables a este tipo de testimonios y sin entrar en la polémica acerca del valor testimonial de los documentos notariales.

26 Estos lapsus en grafías, en fórmulas jurídicas latinas, etc. son interpretados por algunos autores como una falta de aptitud en los escribanos, siendo la mayoría involuntarios, ya que se producían en cuanto aquéllos distraían su atención. Sin embargo, J. A. Frago señala 
En numerosas ocasiones nos encontramos ante la vitalidad de fenómenos locales que la pericia escrituraria no ha podido ocultar. Ambas secuencias nos remiten a un origen común que podría relacionarse con la interferencia de la lengua vasca, sobre todo - como ya he aludido anteriormente - en ciertos campos léxicos, especialmente permeables al elemento vasco, 'o al menos a la integración de voces ligadas al ámbito vasco-románico y que pudieron tener una presencia tanto en la vertiente vasca como en el castellano local' (Echenique Elizondo 2005: 62).

Además, hay que señalar en este punto que el interés por esta documentación reside también en el hecho bien conocido de que los textos romances constituyen para ese periodo el vehículo escrito a través del cual podemos tratar de reconocer la presencia de elementos de la lengua vasca. Lo que hay que aceptar es que la irrupción de estos rasgos en la parte expositiva de estos documentos e, incluso en ocasiones, en los moldes protocolarios del documento, presupone posibles exponentes de la variedad local y resultado de la prolongada convivencia vasco-románica. ${ }^{27}$

La observación de diversos rasgos del castellano de Vizcaya en contraste con zonas circunvecinas dibuja el siguiente cuadro de situación.

1. Graficación de la secuencia velar + wa. Esta secuencia gráfica, característica de la scripta gascona y navarra, aparece también en los documentos del corpus. En los documentos analizados, sólo se han recogido las formas plenas para evitar falsas equivalencias. De esta forma, las velares seguidas del diptongo [wa], tanto en posición tónica como átona, se representan en la mayor parte de los casos mediante la secuencia oa. Este recurso a la secuencia oa - en alternancia con $u a$ - se puede comprobar en otros escritos de distinta procedencia, por lo que no se puede considerar este fenómeno como esporádico. Además, estos alógrafos se dan sólo en ciertos términos, debido posiblemente a la propia frecuencia de aparición de cada forma o a su presencia en una determinada tipología documental - en este caso documentación notarial -, que justifica el uso frecuente del término en el discurso, con lo que aumenta la posibilidad de las ocurrencias. ${ }^{28}$

En cuanto a la justificación de su génesis no parece haber unanimidad en las explicaciones. Se ha opinado diversamente, atendiendo en unos casos a la influencia del Euskara (Yndurain 1945: 42), en otros a una fórmula de compromiso entre dos normas latinas quo-co y qua-ca, de tal modo que quoa sería el cruce de quo-ca y goa una imitación de quoa (Alvar 1953: 26), debido a la scripta occitana de los escribas asentados en Navarra (Saralegui 1977: 55 y Libano Zumalacárregui 1977: 76) y finalmente a la influencia de

que ‘la comisión de no importa qué error ortográfico supone - más allá del ocasional desliz debido a causas psicológicas - la manifestación de un relajamiento cultural o de un bajo nivel de formación intelectual' (Frago Gracía 1987: 91).

27 Lógicamente, esta convivencia correspondería a aquellos documentos de Vizcaya, Guipúzcoa, Álava y Navarra.

28 Obsérvese, por ejemplo, la reiterada frecuencia del verbo 'guardar'. 
la scripta navarra en romance o tal vez gascona (Cierbide Martinena 1988: 52-53 y 1998: 40-41). En relación con la posible influencia del Euskara, la presencia de este rasgo en documentos del corpus de Burgos y Cantabria podría invalidar la hipótesis de que la indistinción [oa] - [wa] se deba a una influencia de esta lengua.

2. Secuencia gráfica de vocal palatal + lateral. Otra característica peculiar que encontramos en estos documentos es la utilización de <ill > en la secuencia $<$ il>. Este rasgo - ausente en los estudios de grafemática referidos al ámbito castellano o dialectal - destaca, precisamente, por la regularidad del corpus en la distinción gráfica de alveolar y palatal. La secuencia vocal palatal-lateral se manifiesta sobre todo en un cierto repertorio de voces: pillotaje, pilloto, pylla, codiçillos. Estos ejemplos - coincidentes en algunos casos con los ya señalados por Carmen Isasi - conveniente analizarlos en el contexto de la convivencia de lenguas románica y vasca (Isasi Martínez 1995: 655). Dentro de este contexto, la grafía <ill> aparecería como posible resultado de la palatalización contextual característica de algunas áreas del Euskara, transferida a la pronunciación y por tanto a la grafía, en especial, en aquellas palabras que coexisten en ambas lenguas. Ahora bien, - como ya señala esta misma autora - no puede ignorarse que los datos diatópicos y diacrónicos relativos a la lengua vasca tardomedieval son escasos y deberán ser precisados para asegurar la tesis de una trasferencia en este rasgo. ${ }^{29}$

3. Seseo gráfico. Nos referimos con el término seseo a la indistinción de los resultados de las antiguas predorsales africadas medievales y de las apicoalveolares. ${ }^{30}$ Como se constata en los resultados de los diferentes corpora, este tipo de confusiones aparece en diferentes territorios del centro-norte peninsular. Ahora bien, por los testimonios recogidos y, sobretodo, por su recurrencia en documentos del País Vasco, no parece demasiado arriesgado aceptar que el fenómeno de la confusión debió de tener más arraigo en esta zona. Lógicamente, hay un elemento a tener en cuenta y es la desigual distribución, aún en documentos coetáneos de la misma tipología. Podemos pensar que su aparición quedó ocultada por la presión de la propia enseñanza escrituraria; es decir, que las confusiones a las que denominamos 'seseo gráfico' no serían más que lapsus calami. Ahora bien, no podemos obviar también la posibilidad de que estos trueques sean el resultado de un contraste en el sistema fonológico del escribano o amanuense. Lógicamente, esta segunda posibilidad se correspondería con los documentos en

29 Lógicamente, hay que tener en cuenta las limitaciones de nuestro propio conocimiento diacrónico de los dialectos vascos, que no permite presentar como causa segura un fenómeno que podría no estar difundido en la lengua origen de la transferencia.

30 Estas confusiones entre dento-alveolares africadas y apico-alveolares fricativas vienen a sumarse a las ya señaladas por Carmen Isasi para el territorio de Bizkaia. Las reflexiones recientes sobre la neutralización de elementos apicales y predorsales en la documentación vizcaína y la identificación en estas grafías de un seseo vizcaíno se pueden observar en diferentes artículos de esta misma autora, principalmente (Isasi Martínez 1999). 
castellano de la zona vasca, y resultado de la convivencia de lenguas, en la que el bilingüísmo vasco-castellano sería piedra angular en la explicación de su genesis. ${ }^{31}$ Sin embargo, esta hipótesis no puede tener la misma importancia y peso para todas las áreas del País Vasco y todas las épocas (Hualde 2010).

La importancia de estos testimonios identificados reside sin duda en su cronología; y como señala Carmen Isasi, estos trueques nos permiten identificar la confusión en una etapa anterior a la generalización de la interdental castellana y nos obligan a replantear si el rechazo de esta articulación por parte de los hablantes de lengua vasca es la única clave para el entendimiento de la cuestión ${ }^{32}$ (Isasi Martínez 2002: 141).

La presencia de este mismo rasgo en documentos de zonas adyacentes al área vasca nos impulsa a reflexionar sobre diferentes interrogantes centrados en la evolución consonántica del castellano y en el incompleto capítulo de la historia de la lengua vasca. ${ }^{33}$

4. Léxico peculiar. Principalmente, se trata de un léxico de origen euskaldun o románico identificado sobre todo en campos ligados a actividades más específicas de la zona, como la pesca, ferrería, empleo del terreno, etc. Algunas de estas voces ya son analizadas en el trabajo de Gómez et al. (2005).

\section{Análisis de documentos notariales}

El análisis de este tipo de documentos notariales nos muestra - al menos para la lengua escrita - muchos aspectos de las innovaciones y las evoluciones areales o temporales. No hay que olvidar que sólo con el análisis de un tipo documental concreto y en un corte sincrónico similar, algunos de estos rasgos identificados en el castellano de los documentos vizcaínos se han localizado también en otras áreas del norte peninsular. ${ }^{34}$ Cierto es que la distribución de esos rasgos

31 Nos estamos refiriendo a hablantes euskaldunes o diglósicos.

32 En este mismo trabajo, ya señala Carmen Isasi que el origen de las confusiones debe hallarse bien en los alófonos de las predorsodentales africadas sorda y sonora, predominantes en el castellano de la zona, bien en el propio sistema de sibilantes del Euskara, donde podría darse la neutralización de las fricativas que los vasquistas describen hoy día para algunas áreas.

33 Es decir, y tal y como señala José Ignacio Hualde, al evaluar hechos de seseo gráfico en documentos de la zona vascófona escritos en castellano es fundamental tener en cuenta si en la época y región específicas de donde procede el documento se habían neutralizado las sibilantes vascas o no. Las preguntas que debemos hacernos son, pues, ¿dónde y cuándo se origina la pérdida de distinción entre la ese y la zeta vascas y cuál es la extensión de este fenómeno de neutralización en distintas épocas? Otra pregunta, más difícil de contestar es la de ¿por qué ocurre este fenómeno? (Hualde 2010).

34 Cuando nos referimos al castellano de Vizcaya, creo que hay que ir valorándolo en su perfil de variedad areal dentro del espacio norteño, en el marco de los estudios ya realizados con anterioridad por Pedro de Múgica (1892) o Vicente García de Diego (1979), y recientemente por Carmen Isasi. En esta línea, esta investigadora ya alude a la presencia en los documentos vizcaínos de "testimonios de formas o procesos que contrastan con el "estandar castellano” comúnmente descrito en las Historias de la Lengua y las Gramáticas Históricas, 
Table 1. Ejemplario de fenómenos

\begin{tabular}{|c|c|c|c|c|c|c|}
\hline & Vizcaya & Guipúzcoa & Álava & Cantabria & Burgos & Navarra \\
\hline 1. Koa & $\begin{array}{l}\text { agoa, } \\
\text { Bermeo } \\
\text { [1517] } \\
\text { goardar, } \\
\text { Bilbao } 1587 \\
\text { ygoalado, } \\
\text { Lekeitio } \\
1545\end{array}$ & 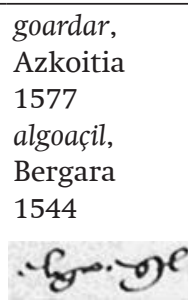 & $\begin{array}{l}\text { quoales, } \\
\text { Agurain } \\
1543\end{array}$ & $\begin{array}{l}\text { goardian, } \\
\text { Castro } 1550 \\
\text { goarda, } \\
\text { Laredo } \\
1598 \\
\end{array}$ & $\begin{array}{l}\text { goardian, } \\
\text { Medina de } \\
\text { Pomar } 1522 \\
\text { gsoafbrart }\end{array}$ & 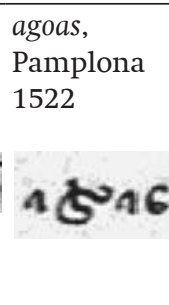 \\
\hline 2. Ill - il & $\begin{array}{l}\text { pillotaje, } \\
\text { Bermeo } \\
1531 \\
\text { pillotos, } \\
\text { Lekeitio } \\
1554 \\
\text { ducesure }\end{array}$ & $\begin{array}{l}\text { pilloto, } \\
\text { Azpeitia } \\
1597 \\
\text { pylla, Esko- } \\
\text { riatza 1579 }\end{array}$ & $\begin{array}{l}\text { utyllidad, } \\
\text { Valdegovia } \\
1548 \\
\text { codiçillos, } \\
\text { Labastida } \\
1508\end{array}$ & $\begin{array}{l}\text { pilloto, } \\
\text { Castro } 1550\end{array}$ & & $\begin{array}{l}\text { çevilles, } \\
\text { Pamplona } \\
1522\end{array}$ \\
\hline 3. Seseo & $\begin{array}{l}\text { aransel, } \\
\text { Mundaka } \\
1579 \\
\text { vesinos, } \\
\text { Meñaka } \\
1598 \\
\text { probinsiana, } \\
\text { Bilbao 1597 }\end{array}$ & 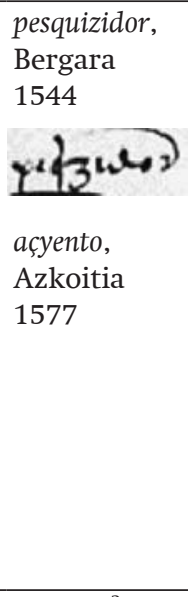 & $\begin{array}{l}\text { mezes, } \\
\text { Labastida } \\
1508 \\
\text { sinquenta, } \\
\text { Laguardia } \\
1554 \\
\text { piessa, } \\
\text { Salvatierra- } \\
\text { Agurain } \\
1543\end{array}$ & $\begin{array}{l}\text { cresen, } \\
\text { Castro } \\
1550 \\
\text { q.SeM } \\
\text { onse, Laredo } \\
1598\end{array}$ & $\begin{array}{l}\text { asierto, } \\
\text { Miranda de } \\
\text { Ebro } 1511 \\
\text { Mact? }\end{array}$ & $\begin{array}{l}\text { setesientos, } \\
\text { Viana } 1537\end{array}$ \\
\hline 4. Léxico & $\begin{array}{l}\text { soliba, }{ }^{1} \\
\text { Lekeitio } \\
1545 \\
\text { batelero, }^{2} \\
\text { Lekeitio } \\
1554\end{array}$ & $\begin{array}{l}\text { Chantel, }^{3} \\
\text { Eskoriatza } \\
1579 \\
\text { Abeurra, } \\
\text { Elgeta } 1597\end{array}$ & $\begin{array}{l}\text { Çurijano, } \\
\text { Agurain } \\
1543 \\
\text { Canton, }^{6} \\
\text { Barrundia } \\
1520\end{array}$ & $\begin{array}{l}\text { Cay, }{ }^{7} \text { Laredo } \\
1598\end{array}$ & & $\begin{array}{l}\text { Estolda, } \\
\text { Pamplona } \\
1522\end{array}$ \\
\hline
\end{tabular}

\section{Notes to Table 1}

1 Proviene del término 'solivo', madero de sierra o viga que se usa como poste o sostén, y que según el DRAE se trataría de un provincialismo de Guipúzcoa y Navarra.

2 De batel, bote o barco pequeño. Entendiendo por el individuo que gobierna el batel.

3 La definición de este término se corresponde con la que describe el DEEH que presenta chartel como voz vasca que significa 'lote de tierra'; o con la del DALV que define txartel como 'porción determinada de un campo labrado', 'finca o heredad muy pequeña', 'lote de terreno'. 
4 Del Euskara abeurrea, señal para identificar la parcelación del terreno. Registrado en el DEEH como 'Señal que ponen en Vizcaya en terreno público para adquirir derecho de edificar en él'. Igualmente aparece con ese significado en los diccionarios vascos. Véase Isasi Martínez (2000).

5 Se trata de una variante que según las citas del DCECH no debió de ser común en castellano, pero que ya la recogen Isasi Martínez (2000) y Gómez (2000) en documentos de Bilbao.

6 Nos referimos a la cuarta acepción del DRAE, quien lo sitúa en Bilbao, Álava y Aragón como 'calleja que corta dos calles principales [...]'.

7 Según el DCECH es voz de origen galorrománico difundida por las costas del Cantábrico, donde encontramos el asturiano cay 'muralla, defensa contra el mar, muelle', cae y cai 'muelle'. En euskara su equivalente es kai, que significa 'puerto' en Gipuzkoa y Bizkaia, y 'muelle' en Hondarribia.

8 Se trata de un término relacionado con el léxico técnico utilizado en las ferrerías, pero de uso común, si bien no está para el castellano en DCECH, en CORDE ni actualmente en DRAE. Sus diferentes acepciones son 'alcantarilla, caño en que se vierte y se le da salida a la escoria del hierro en las ferrerías' y, con un sentido más global, 'alcantarilla bajo los caminos' (DALV 1976-1989).

peculiares no es homogénea, pero, como ya han señalado numerosos investigadores, la aparición de estos fenómenos no carecen de valor informativo, y en palabras de Carmen Isasi, 'porque puede tratarse precisamente de elementos del idiolecto del redactor que escaparían a la presión del modelo tipológico o al “estándar”' (Isasi Martínez 2000: 284). ${ }^{35}$

La lengua de estos documentos muestra en los procesos evolutivos graficofonéticos los rasgos fundamentales del castellano de la época en los que son también visibles la variación y la convivencia de estadios. Al mismo tiempo, aunque con presencia muy restringida, hay también algunos componentes lingüísticos que hacen pensar en ciertas peculiaridades areales ${ }^{36}$. Los documentos vizcaínos del corpus comparten a menudo estas peculiaridades con otros ámbitos limítrofes: algunas coinciden con la scripta guipuzcoana, alavesa o navarra, algunas también al castellano del norte de Burgos o Cantabria. Este aspecto de los resultados del análisis, pese a sus limitaciones, concuerda con lo ya propuesto por Carmen Isasi:

El espacio bilbaíno y Vizcaya se nos presentan, pues, como candidatos óptimos para el estudio de ese 'blanco' en los estudios de dialectología e historia de la lengua ya señalado hace años por María Teresa Echenique y que constituye un 'eslabón perdido' en el complejo dialectal castellano en cuya reconstrucción histórica se trabaja hoy día desde distintas áreas'. (Isasi Martínez 2000: 151)

y que coinciden en cambio y/o con los de ámbitos dialectales próximos, y también en muchos casos - aspecto que quiero subrayar aquí - con los del mismo castellano del norte de Castilla la Vieja' (Isasi Martínez 2006: 213).

35 Lógicamente, hay que tener en cuenta las circunstancias personales en las que se desarrolla y produce el texto, no es raro, que localicemos en los textos concurrencias de rasgos menos habituales, bien porque el escribano, escribiente o amanuense era menos instruido, bien porque estaba apremiado por la prisa o el cansancio.

36 Ya hace unos años Fernando González Ollé señaló en relación con el castellano del norte de la actual provincia de Burgos que algunos de sus rasgos 'presentan indudable carácter peculiar dentro del área burgalesa, en relación, por el contrario, con otras áreas dialectales' (González Ollé 1964: 14). 
Por otro lado, entre las características que se han mencionado aquí, las más específicas entre la documentación vizcaína son la realización palatal de $i l$, el seseo y la presencia de vasquismos entre el léxico. Esta presencia del euskera se constata no sólo en los documentos donde la convivencia entre el euskera y el romance ha sido habitual sino también en territorios en los que la presencia de la lengua vasca se extinguió en tiempo pretérito.

Los testimonios que hemos presentado parten de unos textos escritos en castellano pero sometidos a un importante condicionamiento propio del lenguaje o formulismo notarial. Por tanto, la presencia de la lengua vasca se limita a algunos elementos gráfico-fonéticos y léxicos que tienen su correspondiente paralelo en vascuence, sobre todo en aquellos términos de origen románico o vasco utilizadas en ambas lenguas.

En definitiva, debemos de incrementar nuestro conocimiento de la documentación del País Vasco, pero también el de sus circunvecinas, porque sólo en un marco suficientemente amplio de referencias contrastadas podremos confirmar si los rasgos que hemos señalado en este castellano son o no específicos, y después, si tal especificidad es compartida por otras áreas del continuo norteño. Además, y según se ha podido observar a través del análisis diplomático, estos documentos judiciales aunque están muy ligados al formulismo, no están constreñidos por él, atestiguando en la lengua escrita muchos aspectos de las innovaciones y las evoluciones areales o temporales; y ratificando el interés por este tipo de documentación y poniendo de relieve la necesidad de abordar estudios sobre el notariado hispánico, sobre todo centrados en la figura del escribiente y amanuense que son, en definitiva, las personas que redactan la mayor parte de estos textos.

\section{Obras citadas}

Alvar, Manuel, 1953. El dialecto aragonés (Madrid: Editorial Gredos).

Bono y Huerta, José. Los archivos notariales. Sevilla: Junta de Andalucía, Dirección General del Libro, Bibliotecas y Archivos, D.L. 1985.

Cierbide Martinena, Ricardo, 1988. Estudio Lingüístico de la documentación medieval en lengua occitana de Navarra (Bilbao: EHU/UPV).

-, 1998. 'Notas gráfico-fonéticas sobre la documentación medieval Navarra', en Jóse Manuel Blecua (ed.), Estudios de grafemática en el dominio hispánico (Salamanca: Instituto Caro y Cuervo).

CORDE, s.d. Real Academia Española. Banco de datos. Corpus diacrónico del español. En linea: http://www.rae.es (fecha de la consulta: 11 enero 2010).

Corominas, Joan, y José Antonio Pascual, 1991-1997. Diccionario crítico etimológico castellano e hispánico (Madrid: Editorial Gredos).

DALV (Diccionario Retana de Autoridades de la Lengua Vasca), 1976-1989 (Bilbao: La Gran Enciclopedia Vasca).

DCECH (Diccionario critic etimológico castellano e hispánico), véase Corominas y Pascual 1991-1997.

DEEH (Diccionario etimológico español et hispánico), véase García de Diego 1954.

DRAE (Diccionario de la Lengua Española de la Real Academia Española), véase Real Academia Española 2001.

Echenique Elizondo, María Teresa, 2005. 'La lengua vasca en la historia lingüística española', en Rafael Cano (coord.), Historia de la lengua española (Barcelona: Ariel), pp. 56-89.

—, 2006. 'Historia lingüística vasco-románica: tareas acabadas y perspectivas futuras / Euskera eta inguruko erromantzeen arte harreman historikoak: eginak eta eginkizunak’, Oihenart. 
Cuadernos de Lengua y Literatura, 21: 25-44.

Frago Gracia, Juan Antonio, 1987. 'Rasgos de fonética dialectal en textos periodísticos andaluces', Lingüística Española Actual, 9: 153-74.

García de Diego, Vicente, 1950. 'El castellano como complejo dialectal y sus dialectos internos', Revista de Filología Española, 34: 107-24.

-, 1954. Diccionario etimológico español e hispánico (Madrid: S.A.E.T.A.).

-, 1979. Manual de Dialectología Española (Madrid: C.S.I.C.).

Gómez, Josu, 2000. Vocabulario popular de Bilbao (Bilbao: La Gran Enciclopedia Vasca).

Gómez, Josu, María Soledad Gancedo, Carmen Isasi, Sara Gómez, José Luis Ramírez, Asier Romero y David Alvarez, 2005. 'Léxico vizcáino', Oihenart: cuadernos de lengua y literatura, 20: 73-201.

González Ollé, Fernando, 1964. El habla de La Bureba. Introducción al castellano actual de Burgos (Madrid: C.S.I.C.).

Halliday, M. A. K., 1978. Language as Social Semiotic (Londres: Arnold).

Hualde, José Ignacio, 2010. 'Neutralización de sibilantes vascas y seseo en castellano'. Conferencia impartida en la Universidad de Deusto, 15 de junio de 2009.

Isasi Martínez, Carmen, 1995. 'II-ill, ¿alternancia gráfica o palatalización vasca?', ASJU, 20: 651-59.

-, 1998. 'El ars notariae de los escribanos vizcaínos en el tránsito a la modernidad', in Adolfo Itziar Turrez y Carmen Isasi Arejita (eds), Studia Philologica in Honorem Alfonso Irigoien (Bilbao: Universidad de Deusto), pp. 107-23.

-, 1999. 'Seseo, “ese” sigmática y edición de textos vascos', Fontes Linguae Vasconum, 81: 227-40.

-, 2000. 'Los documentos notariales: entre el formulismo y la innovación', en Elena Artaza y Carmen Isasi (eds), Estudios de Filología y Retórica en Homenaje a Luisa López Grigera (Bilbao: Universidad de Deusto), pp. 281-94.

-, 2002. 'Castellano y Euskera en la documentación de Bilbao', en Adolfo Arejita, Ana Elejabeitia, Carmen Isasi y Joan Otaegi Bilbao (eds), El espacio lingüístico. Simposio 700 Aniversario (Bilbao: Universidad de Deusto), pp. 135-52.

-, 2006. 'El romance de los documentos vizcaínos en el espacio variacional castellano', Oihenart: Cuadernos de Lengua y Literatura, 21: 209-27.

Las Siete Partidas, 1999. Edición facsimilar de la edición de 1555, con glosas de Gregorio López (Madrid: Boletín Oficial del Estado).

Líbano Zumalacárregui, Ángeles, 1977. El Romance Navarro en los Manuscritos del Fuero Antiguo del Fuero General de Navarra (Pamplona: Institución Príncipe de Viana).

-, 2002. 'Vestigios de romance en los documentos notariales de la Alta Edad Media de la mitad norte peninsular', en María Teresa Echenique y Juan Sánchez Méndez (eds), Actas V Congreso Internacional de Historia de la lengua Española (Madrid: Gredos), I, pp. 1261-71.

Lorenzo Cadarso, Pedro Luis, 1999. La documentación judicial en la época de los Austrias. Estudio Archivístico y técnico (Cáceres: Universidad de Extremadura).

Múgica, Pedro de, 1892. Dialectos castellanos, montañés, vizcaíno, aragonés (Berlín: Heinrich \& Kemke).

Penny, Ralph, 2004. Variación y cambio lingüístico en español (Madrid: Gredos).

Real Academia Española, 2001. Diccionario de la Lengua Española (Madrid: Real Academia Española).

Real Díaz, José Joaquín, 1991. Estudio diplomático del documento indiano (Madrid: Dirección de archivos estatales).

Rodríguez Adrados, Antonio, 2005. 'Una valoración de la Pragmática de Álcala', Anales de la Academia Matriatense del Notariado, 43: 632-39.

Rojas Mayer, Elena Malvina, 2002. 'Relevancia y estructuración del discurso en los documentos coloniales de América', en María Teresa Echenique Elizondo y Juan Pedro Sánchez Méndez (coord.), Actas del V Congreso Internacional de Historia de la Lengua Española (Madrid: Gredos), I, pp. 179-206.

Romero Andonegi, Asier, 2008. 'Grafías COA-, GOA-, QUOA- en documentación tardomedieval vizcaína [Bermeo]', RILCE: Revista de Filología Hispánica, 24: 388-406.

-, 2009. 'Grafías de sibilantes y representaciones de ese sigmática en documentos de Bermeo', Fontes Linguae Vasconum: Studia et Documenta, 41: 99-116. 
BHS, $90(2013)$

Santiago Lacuesta, Ramón, 1977. 'Notas sobre la lengua y escribanos en documentos medievales alaveses', Boletín del Instituto Sancho el Sabio, 21: 235-57.

Saralegui, Carmen, 1977. El dialecto navarro en los documentos del monasterio de Irache [958-1397] (Pamplona: Institución Príncipe de Viana).

Terrado Pablo, Javier, 1991. La lengua de Teruel a fines de la Edad Media (Teruel: Instituto de Estudios Turolenses).

Wesch, Andreas, 1994. 'El documento indiano y las tradiciones textuales en los siglos XV y XVI: la clase textual información', en Jeans Lüdtke (ed.), El español de América en el siglo XVI (Frankfurt, Germany: Vervuert), pp. 57-71.

Yndurain, Francisco, 1945. Contribución al estudio del dialecto navarro-aragonés antiguo (Zaragoza: El noticiero).

\section{APÉNDICE 1}

\section{Fuentes primarias}

\section{Documento 1}

1514. Octubre 13. Bermeo (Vizcaya).

Pleito entre Martín Abad de Artadi y María Juana de Hermendurua, mujer de Ochoa, por la posesión de un vergel.

Archivo de la Real Chancillería de Valladolid. Sección Pleitos de Vizcaya. Leg. 606-06.

\section{Documento 2}

1517. Febrero 12. Bermeo (Vizcaya).

Probanza realizada a petición de la orden franciscana en el pleito entre el convento de franciscanos y los dueños de unas casas que se encontraban delante del convento y que esta congregación las quería derribar.

Archivo General de Simancas. Memoriales. Leg. 122, $\mathrm{n}^{\circ} 74$.

\section{Documento 3}

1527. Mayo 02 - 1527. Diciembre 27. Bermeo (Vizcaya).

Probanza realizada por Juan González de Mugica en el pleito que mantiene con Martín Ruíz de Apioça por la elección de oficios en el concejo.

Archivo de la Real Chancillería de Valladolid. Sección Pleitos de Vizcaya. Leg. 118-10.

\section{Documento 4}

1527. Abril 06 - 1527. Diciembre 27. Bermeo (Vizcaya).

Probanza realizada a petición de Martín Ruiz de Apioza en el pleito que mantiene con Juan González de Mugica por la elección de oficios en el concejo.

Archivo de la Real Chancillería de Valladolid. Sección Pleitos de Vizcaya. Leg. 118-10.

\section{Documento 5}

1531. Mayo 8. Bermeo (Vizcaya).

Probanza realizada a petición de San Juan de Arostegui en el pleito entre San Juan de Arostegui, preboste de la villa de Bermeo, y Rogel Pavin Ingles, sobre los derechos de prebostad por el arribo de la nao Rochel Peyon Primerosa a Bermeo con carga de trigo.

Archivo de la Real Chancillería de Valladolid. Sección Pleitos de Vizcaya. Leg. 68-08.

\section{Documento 6}

1587. Junio 18. Bilbao (Vizcaya).

Probanza realizada por Joan de Eguia, síndico procurador general del Señorío de Vizcaya, sobre varios testigos para informar sobre las beneficiosas acciones de las religiosas de la orden de San Francisco en Bilbao e impedir que guardasen clausura.

AHEB-BEHA. Fondo del señor Santiago de Bilbao, 0769/023-00. 


\section{Documento 7}

1585. Mayo 23. Meñaka (Vizcaya).

Probanza con las preguntas que se hicieron a los testigos presentados por la Anteiglesia de Meñaca en la causa contra Juan de Echavarria Batiz sobre la elección de fieles regidores de ella.

AHEB-BEHA. Fondo del señor Santiago de Bilbao, 0830/000-00.

\section{Documento 8}

1579. Mundaka (Vizcaya).

Pleito de Gracia de Basterrechea, de Mundaca y Pedro de Acurio, de Mundaca sobre los alimentos y crianza de una niña.

Archivo de la Real Chancillería de Valladolid. Sección Pleitos de Vizcaya. Leg. 1273.0002.

\section{Documento 9}

1502. Abril 30. Gernika (Vizcaya).

Testimonio de preguntas en el pleito de Martín Fernández de Urramendi, de Guernica, Juana de Meceta, de Guernica, Sancho Martínez de la Rentería y Juan Pérez de Marmese sobre los bienes que quedaron a la muerte de Juan Pérez de Marmese.

Archivo de la Real Chancillería de Valladolid. Sección Pleitos de Vizcaya. Leg. 0118.0001.

\section{Documento 10}

1545. Junio 16. Lekeitio (Vizcaya).

Articulado de preguntas para examinar los testigos de parte del concejo de la Villa de Lequeitio en el pleito criminal contra Miguel de Leaegui y consortes, sobre la posesión de las dos tercias partes del monte de Burgaña, y haber roto dicho Miguel una importante parte de terreno haciendo novalías y heredades.

Archivo Municipal de Lekeitio. Registro 3, $\mathrm{n}^{\circ} 34$.

\section{Documento 11}

1554. Agosto 30. Lekeitio (Vizcaya).

Articulado de preguntas y examen de testigos, por ante Ochoa Urtiz de Olea, y Anton Martinez de Traiña escribanos reales, en la Villa de Lequeitio a 30 de Agosto de 1554 para el pleito que trataron con el Concejo de ella, Miguel de Burgueina y Martin Ruiz de Ybarra, sobre los carbones y rozaduras del monte de Burgueña.

Archivo Municipal de Lekeitio. Registro 3, $\mathrm{n}^{\mathrm{o}} 22$.

\section{Documento 12}

1597. Azpeitia (Guipúzcoa).

Carta receptoria y probanza para un pleito por la herencia de Juan López de Zarauz y Ana Pérez de Aldamar.

Archivo Municipal de Azpeitia. Expedientes Judiciales. 646-08.

\section{Documento 13}

1577. Azkoitia (Guipúzcoa).

Probanza hecha de parte de doña Cathalina de Manchola en el pleito que trataba con María de Aranzaga sobre una casa y huerta en esta villa de Azcoitia.

Archivo Municipal de Azkoitia. Leg. 79, $\mathrm{n}^{\circ} 2$.

\section{Documento 14}

1544. Bergara (Guipúzcoa).

Probanza de Juan de Vergara, oidor de las cuentas reales y juez de finanzas del Reino de Navarra, del pleito que trata en Valladolid, sobre 600 escudos de oro del sol.

Archivo Municipal de Bergara. Pleitos civiles. C/235-01. 
Ejemplario documental

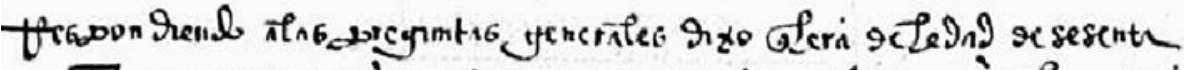

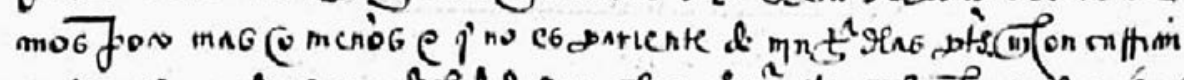

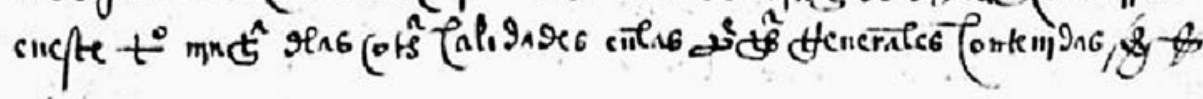

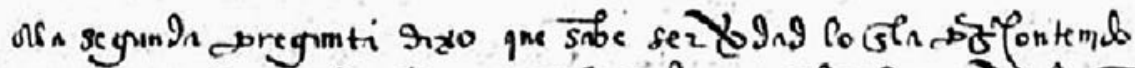

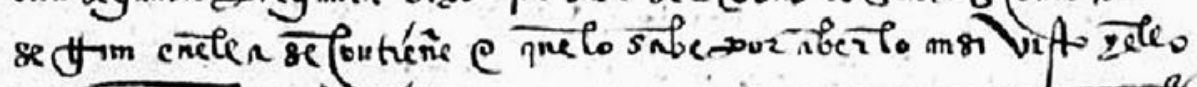
ce notorio conflio/s

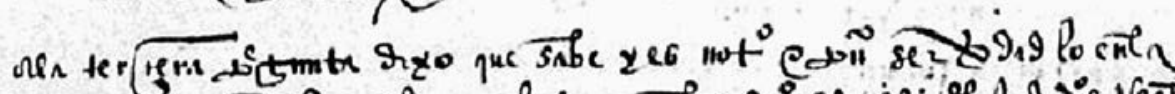

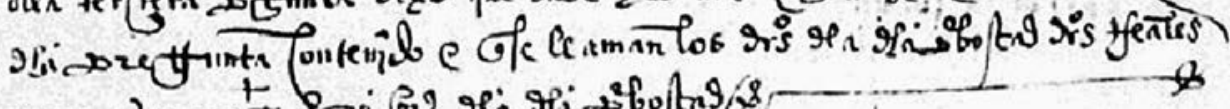

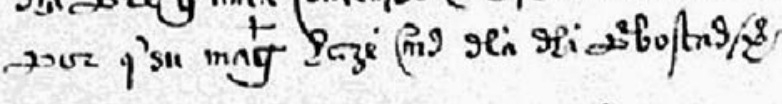

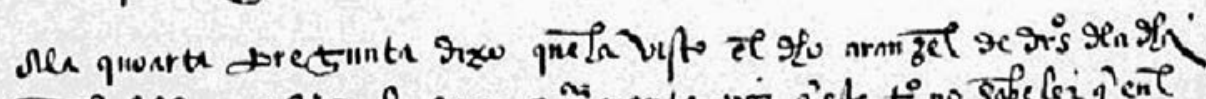

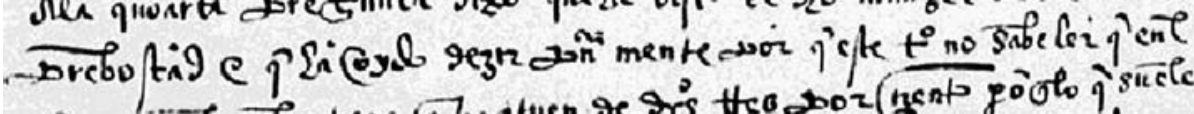

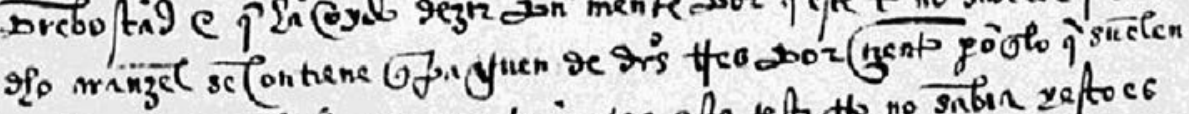

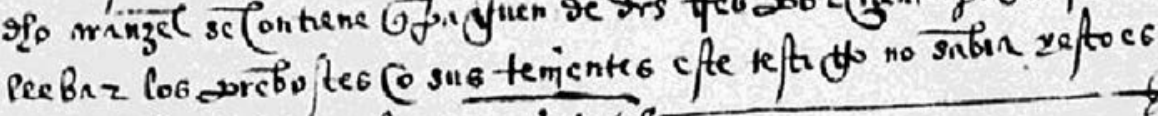

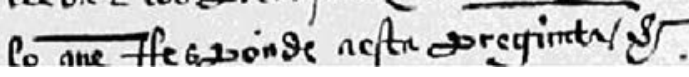

Documento 5 Bermeo 1531.

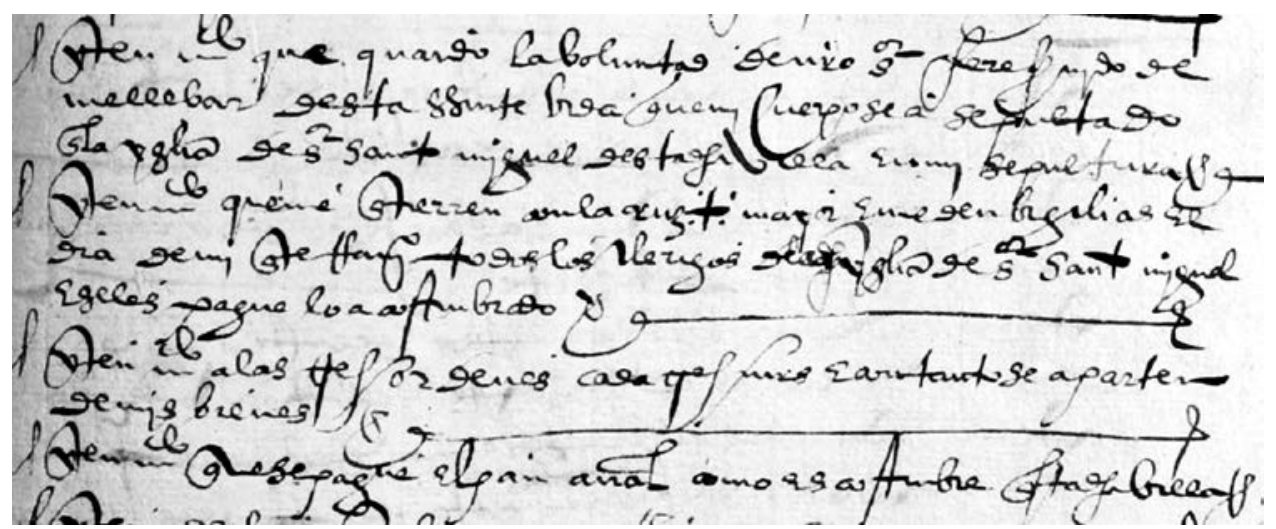

Documento 16 Elgeta 1596.

Documento 15

1512. Oñati (Guipúzcoa).

Expediente de la probanza hecha por la villa de Oñate en el pleito de primera instancia con el Conde sobre que en ocasiones de guerra la villa de Oñate y sus vecinos iban bajo la Hermandad de Guipuzcoa y no del Conde.

Archivo Municipal de Oñati. Expedientes judiciales. Pleitos civiles. Caja 834 exp. 2. 


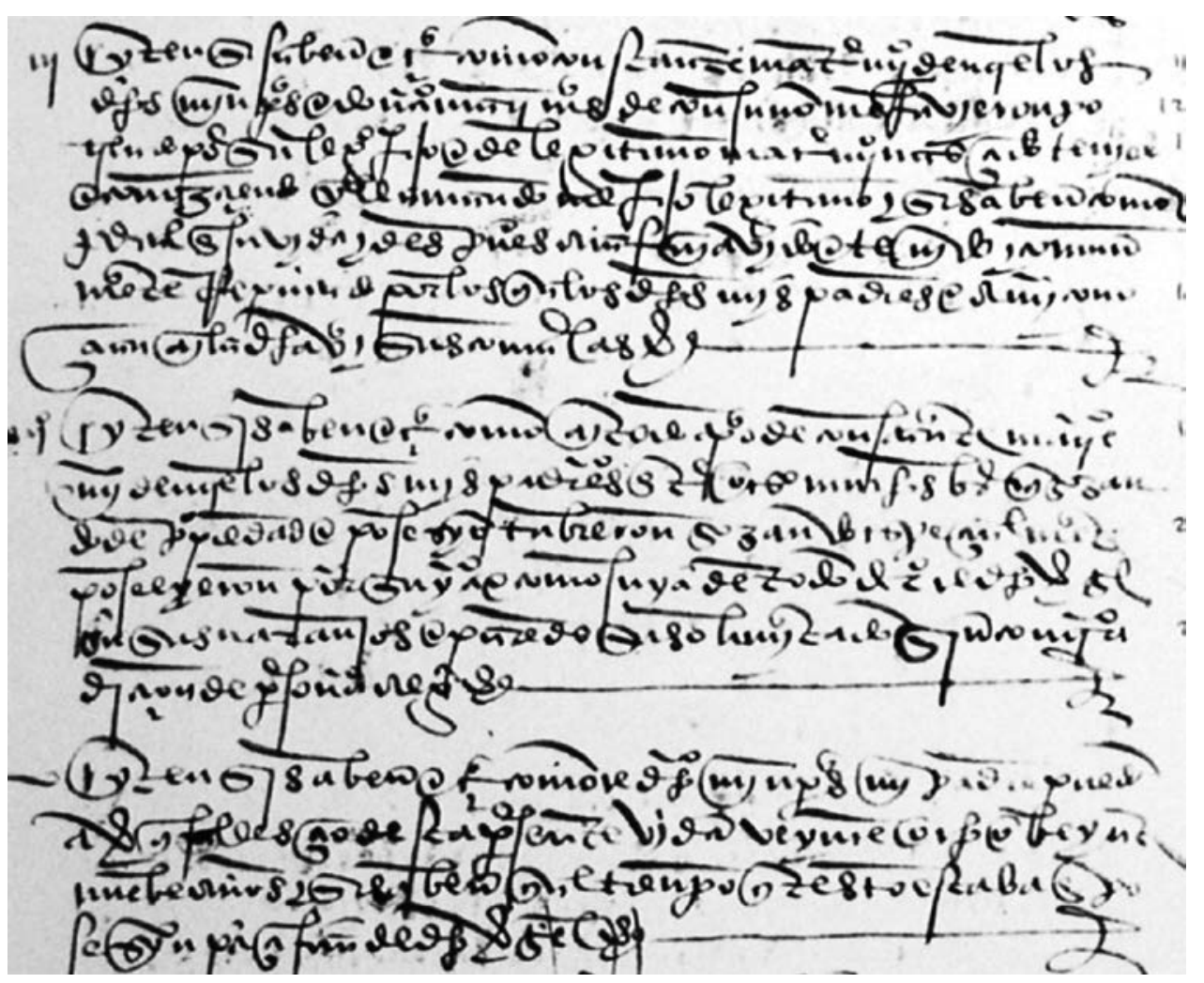

Documento 15 Oñati 1512.

Documento 16

1597. Elgeta (Guipúzcoa).

Testimonio de Antonio de Arcaraso por la venta de un castañal.

Archivo Histórico de Protocolos de Gipuzkoa. Sign. 11895.

\section{Documento 17}

1579. Eskoriatza (Guipúzcoa).

Testimonio de francisca de Zavala por el arrendamiento de una casa.

Archivo Histórico de Protocolos de Gipuzkoa. Sign. 12009.

\section{Documento 18}

1543. Salvatierra-Agurain (Álava).

Probanzas hechas por los concejos de Narvaja y Aspuru en el pleito con las monjas del monasterio de Barria, en virtud de una provision real.

Archivo del Ayuntamiento de Salvatierra/Agurain. C. 17, $\mathrm{n}^{\circ} 18$.

\section{Documento 19}

1548. Valdegovía (Álava).

Pleito de Juan de Salazar, Juan Ruiz de Ángulo y Juan Ortiz de Uribe, todos hidalgos y vecinos respectivamente de Nograro, Quejo y Gurendes, anejos de Valdegovía (Álava), con los pecheros del valle de Valdegovía sobre haberles tomado y prendido objetos de su propiedad.

Archivo de la Real Chancillería de Valladolid. Sala de Hijosdalgo, caja 148/25. 


\section{Documento 20}

1554. Laguardia (Álava).

Pleito de Juan de Maeztu sobre la restitución de ciertas casas situadas en la calle Mayor de Laguardia.

Archivo de la Real Chancillería de Valladolid. Sección Pleitos Civiles, Pérez Alonso, caja $603 / 7$.

\section{Documento 21}

1508. Labastida (Álava).

Pleito de María Fernández de Angulo, viuda de Lope de Cariga, contra Lope de Cariga, Diego López de Salazar y demás consortes y herederos de Ochoa de Cariga, sobre la división de los bienes y herencia de Ochoa de Cariga.

Archivo de la Real Chancillería de Valladolid. Sección Pleitos Civiles, Fernando Alonso, caja $200 / 5$.

\section{Documento 22}

1520. Barrundia (Álava).

Pleito de Juan Ochoa de Zárate, por sí y en nombre de los hidalgos de las hermandades de Cigoitia, Ariñez, Barrundia y Arrazua, en Alava, con Hurtado Díaz de Mendoza, gobernador y justicia mayor de la tierra, sobre nombramiento de alcalde de Foronda al pechero Juan Pérez de Betolaza, por ser contrario a los privilegios de la villa y al contrato que hizo la provincia cuando voluntariamente se incorporó a la Corona de Castilla.

Archivo General de Simancas, Consejo Real de Castilla, sign. 49/4.

\section{Documento 23}

1598. Laredo (Cantabria).

Autos y diligencias en el pleito entre Juan de Rivas Santibáñez y Juan de Borroto, vecinos de Laredo y miembros de la Cofradía de San Martín, sobre el ejercicio del cargo de procurador general de la misma.

Archivo Histórico Provincial de Cantabria, Cofradía de San Martín, legajo 10, núm. 12.

\section{Documento 24}

1550-1597. Castro Urdiales (Cantabria).

Protocolo notarial de Peñavera, Carlos de [padre], escribano de Castro Urdiales.

Archivo Histórico Provincial de Cantabria, Protocolos notariales, legajo 1706.

\section{Documento 25}

1488-1566. Medina de Pomar (Burgos).

Testificación de Juan Sánchez, en el pleito contra Juan de Vallejo, vecinos de Medina de Pomar (Burgos).

Archivo de la Real Chancillería de Valladolid. Sección Pleitos Civiles, Alonso Rodríguez, caja 1312-6.

\section{Documento 26}

1511. Miranda de Ebro (Burgos).

Pleito de Fernando de Zárate, vecino de Miranda de Ebro.

Archivo de la Real Chancillería de Valladolid. Sala de Hijosdalgo, caja 502-13.

\section{Documento 27}

1522. Pamplona (Navarra).

Pleito de Fuente Hurtado de Traslaviña, de Zalla y Juan de Pamplona sobre restitución de 20 quintales de acero.

Archivo de la Real Chancillería de Valladolid. Sala de Vizcaya, legajo 0092-0002. 


\section{Documento 28}

1555. Estella (Navarra).

Pleito de Convento de Santa Clara, de Estella contra Antonio Hurtado y consortes, pidiendo ejecución de bienes por cuantía de 4.551 maravedíes según una carta de censo.

Archivo de la Real Chancillería de Valladolid. Sección Pleitos Civiles, Fernando Alonso, caja $684 / 2$.

\section{Documento 29}

1537. Viana (Navarra).

Pleito de Juan Beaumont y de Navarra, de Viana (Navarra), Francisco de Porres, de Agoncillo (La Rioja), Concejo, justicia y regimiento de Agoncillo (La Rioja) contra Francisco de Porres, señor de Agoncillo, y el concejo de dicha villa por haber entrado en sus montes a cazar y talar árboles sin tener derecho a ello.

Archivo de la Real Chancillería de Valladolid. Sección Pleitos Civiles, Pérez Alonso, caja $1670 / 2$. 


\section{Colonial Latin American Historical Review (CLAHR)

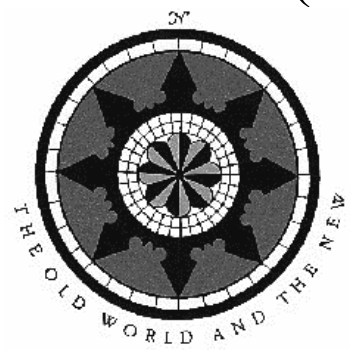 \\ Featuring the COLONIAL ERA \\ IN LUSO-HISPANO AMERICA}

MANUSCRIPT SUBMISSIONS INVITED

Original essays based on archival sources, max. 25-30 pp. + footnotes

3 copies + disk or electronically, Microsoft Word preferred or PC compatible, English or Spanish

\section{Subscription Form:}

Name:

Address:

Telephone:

E-mail:

Individual \$40 Institution \$50 Student \$35 Single Issue \$14 (Add $\$ 5.00$ for areas outside of the United States, Mexico, and Canada)

Check or money order payable to: Colonial Latin American Historical Review

VISA MasterCard Acct.\# Exp. Date

Cardholder's Signature

Billing Address

Please send this form with the appropriate payment to Dr. Joseph P. Sánchez, Editor:

\section{Mailing Address:}

Spanish Colonial Research Center, NPS

MSC05 3020

1 University of New Mexico

Albuquerque NM 87131-0001 USA

\section{Location/Ship To:}

Spanish Colonial Research Center, NPS

Zimmerman Library

1 University of New Mexico

Albuquerque NM 87131-0001 USA 